\title{
Production Costs, Transaction Costs, and Local Government Contractor Choice
}

\author{
WORKSHOP IN POLITICAL THEORY \\ AND POLICY ANALYSIS \\ 513 NORTH PARK \\ INDIANA UNIVERSITY \\ BLOOMINGTON, INDIANA 47405
}

\author{
James M. Ferris, Ph.D. \\ Elizabeth Graddy, Ph.D. \\ School of Public Administration \\ University of Southern California \\ Los Angeles, California 90089-0041
}

July 1989 


\section{Introduction}

As their fiscal conditions have declined and their service obligations have increased, local governments have sought alternative means of service delivery. One alternative which has become increasingly popular is contracting out. Under this arrangement, services are financed by the local government but production of the service is contracted to external suppliers. A growing body of work has explored the contracting decision, but it has focused almost exclusively on the production choice decision: does a local government providing (i.e., financing) a service produce it internally or externally? ${ }^{1}$ The contracting decision has, however, a second part -given the decision to contract out the production of a service, does the local government contract with other governments, with nonprofit organizations, or with profit-making firms??

Contracting is assumed to yield cost-savings by exploiting scale economies, overcoming input rigidities, and capitalizing on managerial and competition-induced efficiency incentives. The ability to achieve these potential cost-savings will vary by the sector of the external producer. Therefore, there is a need to go beyond the production choice decision (internal versus external production), and examine the contractor choice of contracting governments.

The usefulness of this line of inquiry is underscored by contractor choice patterns that indicate that the sector of the contractor varies by service as well as across local governments (Ferris and Graddy, 1986). Understanding the local government's contractor choice from among the three sectors will add insight into the motivations for contracting and, ultimately, enable us to more correctly predict the cost and service quality effects of different external supply alternatives. This paper explores the determinants of the sector choice decision by contracting local governments. In the next section, we examine the production costs and transaction costs associated with organizations from the three sector. Then, we develop a general model of the contractor choice decision and empirically test it using data on local government contract arrangements for three health services: hospital, alcohol/drug prevention and treatment, and mental health.

${ }^{1}$ See, for example, Sonenblum, et al (1977), Ferris (1986), Ferris and Graddy (1988), and Stein (1989).

2

In this paper, we use the terms for-profit firms and nonprofit organizations in reference to privately controlled organizations. Publicly controlled corporations or nonprofit organizations represent considerably different alternative supply arrangements which typically involve off-budget activities and rely on private financing to varying degrees. 


\section{Service Delivery Costs and Contractor Options}

A local government contracting out the production of a service may choose from among three external production alternatives: other government units; nonprofit organizations; or for-profit firms. ${ }^{3}$ We posit that the government, in making the sector choice, seeks to maximize its utility by selecting the alternative that minimizes the costs of service delivery.

There are two components of service delivery costs: production costs and transaction costs. The literature on public service contracting has tended to focus on production costs, with the strong presumption that private production is less costly than public production. This presumption is buttressed by a number of service-specific cost comparisons across sectors (Borcherding et al., 1982). These studies, for the most part, fail to examine cost comparisons in an actual contracting environment, and do not assess the transaction costs that external production involves. There is reason to believe that incorporating transaction costs will reduce the cost savings often attributed to contracting, and may even outweigh the production cost savings. Therefore, in order to accurately evaluate the relative merits of the various sector choices, it is necessary to examine both components of cost, particularly as they relate to the organizational form of the contractor. Consider each cost component in turn.

\section{Production Costs}

Several factors generate a production cost premium for reliance on internal production: scale diseconomies, perverse managerial incentives, and input rigidities. The degree to which these factors can be surmounted by external production and, thus, yield production cost savings depends on the organizational form of the contractor.

Scale economies. With internal production, the production scale is limited by the size of the jurisdiction, and there is little reason to believe that for any given service, the jurisdiction size corresponds to the optimal scale of production. External production separates the production scale decision from jurisdiction size thus allowing scale economies to be realized. Since this source of cost savings results from the shift from

Although we assume that the sector choice is independent of the choice of external versus internal production, the two may be interrelated. For example the two are obviously related if producer availability is an important factor in the initial decision and one sector dominates the available options. 
internal to external production, it does not in theory differentiate among the three external sector options. Of course, in some instances, available external producers might be limited to a particular sector, either for legal ${ }^{4}$ and/or historical reasons. ${ }^{5}$

Managerial incentives. Internal production is subject to the behavioral incentives embodied in all public organizations. These incentives affect the efficiency of public bureaus relative to other organizational forms. There are principal-agent problems arising from the informational advantages of the agents (bureaucrats) over their principals (legislators) which are perceived to increase public production costs. For example, the notion of public bureaucrats as budget maximizers is predicated on the bureau's knowledge of the actual costs of delivering services and the use of this knowledge to increase their budgets (Niskanen, 1971). In addition, the lack of property rights to residuals (the difference between budgets and actual production costs) lessens incentives for bureaucrats to minimize costs. In fact, there are incentives for them to create slack. This slack provides them utility directly, or the resources from which they may derive utility, by creating incentives for subordinates to behave consistently with bureaucratic objectives.

There is reason to believe that public organizations exposed to competitive forces respond more efficiently than those that are not. In order to bid for a contract from another government, the public organization needs to specify outputs and costs. Moreover, it will be more sensitive to minimizing costs since it is no longer operating as a monopolist. ${ }^{-}$Nevertheless, external public organizations still lack many of the incentives to minimize costs that are present in their private sector counterparts.

Private sector organizations embody different managerial incentives from those that characterize public bureaus. In proprietary organizations, the incentive problem can be reduced by giving the manager a property right to a portion of the profits. The

Some states prohibit local government contracting of specific services to the private sector.

\footnotetext{
${ }^{5}$ For example, some cities never established their own production units, and have contracted with larger
} governments throughout their history (Miller, 1981).

6

Mehay and Gonzalez (1985) found that public organizations that supply services to other governments have lower costs. 
calculation of profits and the assignment of property rights, i.e., distribution of profits, to managers enables owners to provide rewards for management to perform in accordance with the owner's interests, i.e., profit maximization. This provides strong incentives for production efficiency.

The nonprofit organization may also make profits; however, it operates under nondistribution and reasonable compensation constraints (Hansmann, 1980). Residuals may not be distributed directly to the board of directors or the managers, although they can be used to extend services, enhance quality, or cross-subsidize unprofitable activities. These constraints make it difficult to devise a scheme to avert agency problems between the board and it managers. Moreover, the lack of a singular objective for nonprofit organizations analogous to the for-profit sector (James and Rose-Ackerman, 1986) makes it difficult to generalize about the incentives inherent in nonprofit organizations. However, in terms of the strength of managerial incentives for cost savings, the nonprofit organization seem to fall between the for-profit firm and the external public organization.

Input rigidities. Another motivation for choosing external production over internal production is the desire to circumvent constraints on managerial discretion in public organizations imposed by civil service and public budgeting systems. Public personnel policies limit the discretion of managers in selecting the optimal combination of labor inputs for a given output. Constraints on hiring, firing, and promotion as well as compensation levels make it difficult for managers to rearrange their staffs and their skill composition to deliver services at minimum costs. In addition, public managers, faced with separate budgetary processes for capital and operating expenditures, do not always have the flexibility necessary to acquire the desired level of capital. Thus, the inability to alter personnel as a result of inflexible civil service systems, as well as constraints on the acquisition of capital embodied in public budgeting systems, make it difficult for public managers to select the optimal mix of inputs from a production cost perspective.

Although the competitive pressures faced by external public organizations enhance

Such a solution is not available in the public bureau for two reasons: 1) the lack of an easily measured profit, i.e., the difficulty of separating revenues from costs due to the lack of explicit prices and outputs; and 2) the difficulty of designing civil service systems to reward individuals based on performance. These two factors are reinforcing; it is difficult to devise a performance-based salary scheme when it is difficult to measure outputs and costs. 
incentives for cost minimization, they do not mitigate the rigidities within the public sector which generate suboptimal utilization of inputs. Thus, external public producers do not offer advantages over internal production with respect to input rigidities.

The lack of such constraints in private organizations, either for-profit or nonprofit, make them attractive contracting options. Moreover, the for-profit sector with its easier access to financial capital may have an advantage over the nonprofit sector (Hansmann, 1980). The inability of nonprofits to sell equity shares limits their ability to finance capital acquisition. In addition, they face more difficulties in borrowing the resources necessary for capital expansion since lending institutions view nonprofit organizations as more risky than for-profit organizations. This gives the for-profit sector an edge in terms of optimal input mix and expansion.

The magnitude of this advantage is limited to the extent that nonprofits are able to secure funding from other sources such as charitable contributions or grants. The ability of nonprofit organizations to generate resources through the donation of either time or money creates input flexibility for the organization. In addition, foundation and government grants can provide needed resources for input acquisition by nonprofits. These sources are typically not available to proprietary organizations.

Therefore, while there is a presumption that external production reduces production costs, the extent of the cost savings will vary by type of external organization. Based on managerial incentives and input rigidities, the for-profit firm should offer the greatest production cost savings, the nonprofit organization somewhat less, and the external public bureau the least. ${ }^{\mathrm{s}}$

\section{Transaction Costs}

Consider now the transaction costs associated with the various organizational choices for the production of publicly provided services. Transaction costs are incurred in an effort to minimize agency problems encountered in contracting with external organizations.

\footnotetext{
Another source of cost savings which is often overlooked in the contracting literature is tax exemption. The differential tax treatment of organizational types has consequences for production costs. The for-profit firm is generally subject to a variety of taxes whereas the the external public and private nonprofit organization is tax exempt. In comparing the private sector contractor choices, this gives the nonprofit sector an advantage. This is illustrated by evidence that the market share of the nonprofit sector is positive and significantly related to preferential tax treatment (Hansmann, 1987).
} 
While there are agency problems internal to the public bureau, the transaction costs associated with external production are typically assumed to be greater. In fact, the production cost savings derived from external producers may be offset by the transaction costs governments incur to reduce the risk of relinquishing control over the production process (Borcherding, 1988).

The dilemma of public service contracting is the extent to which the principal (the contracting government) can assure that the agent (the contractor) will behave so as to meet the principal's objectives in the presence of information asymmetries. The contracting government is not likely to have complete information on the capacity of the different bidders to perform to contract specifications creating an adverse selection problem. To increase the probability of selecting the best contractor, the contracting government may incur costs to gather relevant information. Information asymmetries also create problems at the monitoring and enforcement stage. In cases where it is technically impossible or very costly to monitor performance, there are potential moral hazard problems, i.e., the contractor may be inclined to shirk on performance and thereby "cheat" the contracting government.

The contracting government seeks to minimize these problems through contract design and administration. Transaction costs are incurred in the execution of the contracting process: writing and monitoring contracts. ${ }^{\circ}$ The magnitude of these costs depend on the type of service and on the organizational type. We consider these two sets of factors in turn.

Service-related factors. Contract specification requires that one can define and measure the quantity and quality of the service, and can describe the conditions under which the service will be delivered. Such tasks are facilitated when the service is characterized by relatively constant citizen preferences and relatively stable cost conditions (technology and input prices).

Once a contract is written, it must be monitored. The feasibility of measuring performance is critical. It must be technically possible to measure outputs, both

Transaction costs also include the reduced competition that results over time from asset specificity. For a comprehensive exposition of transaction cost economics see Williamson (1985). 
quantitatively and qualitatively, and at a reasonable cost. This condition is more likely to be met when services are tangible or "hard", e.g., garbage collection or road repair, as opposed to intangible or "soft" services, such as health and child care. Although it is possible to develop quantity measures such as the number of individuals served, the issue of service quality is more vexing.

Organization-related costs. Transaction costs also vary by organizational type. Nonprofit organizations may reduce transaction costs at the contract writing and monitoring stages. One of the alleged virtues of the nonprofit sector is its responsiveness to demands for collective goods, particularly in the case of heterogeneous preferences (Salamon, 1987; Weisbrod, 1988). To the extent that nonprofit organizations operate effectively in these cases, the contract writing costs for government are likely to be decreased, either because the nonprofit organization's record of service provision is satisfactory or the nonprofit organization helps write the contract through cooperative negotiations (e.g., see DeHoog, 1984).

The potential savings in monitoring costs associated with the nonprofit form may be even more important. There is widespread concern that for-profit firms will cut corners on quality to increase profits. Nonprofit organizations, due to the existence of the nondistribution constraint, are often assumed to be more trustworthy. This belief is rooted in the fact that many nonprofit organizations were created as a result of a keen interest in the quantity and/or quality of the service. Consequently, nonprofits may be preferred to for-profit firms when monitoring is difficult (Krashinsky, 1986). In effect, choice of the nonprofit organizational form is. perceived as a method of reducing transaction costs that arise from difficulties of monitoring performance. In addition, the fact that nonprofit organizations often receive considerable donations creates the possibility that individuals making such donations may be in a position to monitor the organization, especially when donations are in the form of volunteering. Similar reasoning applies to external public organizations where the incentives for opportunistic behavior are significantly reduced by the pressures of accountability and the lack of property rights in the public sector.

\section{Availability}

Finally, in examining the full array of organizational choices, it is necessary to underscore the fact that the availability of suppliers across the three external options might be limited. For example, there are a large number of nonprofit suppliers in the social 
services, while there is a dearth of nonprofit suppliers in public works. Thus, the contractor options that the contracting government faces may be constrained.

\section{Summary}

The providing government faces a potential choice of three sectors for the external production of publicly provided services. Critical to choosing among them are their relative advantages with respect to both production and transaction costs. Key factors in the determination of production efficiencies are scale economies, managerial incentives, and input flexibility. Scale economies merely require the ability to produce at a specified level and do not otherwise differentiate the organizational choices. Managerial incentives and input flexibility, however, do differentiate the sectors. Managerial incentives in the for-profit sector are most conducive to minimizing production costs. Key factors affecting transaction costs are the feasibility and costs of writing and monitoring contracts. These costs depend on the nature of the service and organizational type. Internal production minimizes transaction costs; however, among the external options, the public and the nonprofit sectors are likely to be preferred when contract writing and monitoring are difficult.

\section{Contractor Choice Decision}

\section{Decision Rule}

The previous section conceptualizes the tradeoff between production and transaction costs in the contractor choice. The external production option that minimizes production costs also maximizes transaction costs. Therefore, the contractor choice depends on how the local government weighs these two components of service delivery costs.

Production and transaction costs are fundamentally different in their effects. Production costs are visible and have a direct impact on government expenditures, and thus are discussed in the context of budgetary decisions. Transaction costs are more difficult to discern and their impacts are more subtle, e.g, service quality effects, even though they have budget impacts. Therefore in jurisdictions where fiscal concerns are important, production costs may be weighed more heavily than transaction costs.

The general public should prefer the least-cost contractor option for a given service output level and quality. Those who do not directly benefit from the service may prefer 
to minimize the direct production costs since the burden of higher costs falls on them in terms of higher taxes or reduced levels of other services. The service constituents, however, are likely to have different preferences. They are more concerned than the general public with service quality and with the local government's commitment to provision. Service constituents should prefer nonprofit over for-profit production if the nonprofit organizations have a history of provision, have a commitment to service quality, or are presumed to be more trustworthy.

Therefore, we posit the following decision rule. The government decision maker is assumed to maximize utility by choosing the sector that minimizes the weighted sum of production and transaction costs, where the weights reflect the importance of the two cost components to the decision maker.

More precisely, let $y_{i}^{*}$ denote the output level which local government $i$ has decided to produce externally, and let $y_{i j}$ denote the amount of $y^{*}$ produced by sector $j$, where $j$ equals 1 for bureaus of other governments, 2 for nonprofit organizations, and 3 for forprofit firms. Then:

$$
y_{i}^{*}=\sum_{j=1}^{3} y_{i j}
$$

The production and transaction costs associated with producing $v_{i}^{*}$ vary by sector. Let $P C\left(y_{i j}\right)$ and $T C\left(y_{i j}\right)$ be the production costs and transaction costs respectively associated with the external production of output $y$ in sector $j$ and jurisdiction $i$. Then:

$$
P C\left(y_{i}^{*}\right)=\sum_{i=1}^{3} P C\left(y_{i j}\right) \text { and } T C\left(y_{i}^{*}\right)=\sum_{i=1}^{3} T C\left(y_{i j}\right)
$$

The goal of local government $i$ is to select $f$ such that the weighted sum of $P C\left(y_{i}^{*}\right)$ and $\mathrm{TC}\left(\mathrm{y}_{i}^{*}\right)$ is minimized. The weights, $\gamma$ and $\delta$, are functions of political and fiscal forces at work in the jurisdiction and represent the relative importance to the local government of minimizing the two components of service delivery cost. Therefore, the objective function is:

$$
\text { MIN } Y_{i} \sum_{i=1}^{3} P C\left(y_{i j}\right)+\delta_{i} \sum_{j=1}^{3} T C\left(y_{i j}\right)
$$




$$
\text { st } \sum_{j=1}^{3} y_{i j}=y_{i}^{*}
$$

According to our theory, the ordering of production costs by sector for some fixed output $Y$ is:

$$
\begin{aligned}
& P C\left(y_{i 1}\right)>P C\left(v_{i 2}\right)>P C\left(v_{i 3}\right) \\
& \text { where } P C\left(v_{i 1}\right)-P C\left(y_{i 2}\right)=f[I R, M I] \text { and } P C\left(v_{i 2}\right)-P C\left(v_{i 3}\right)=g[M I]
\end{aligned}
$$

IR refers to input rigidities and $M I$ to managerial incentives. These variables determine the difference in production costs across sectors in a jurisdiction.

Our theory predicts the following ordering of transaction costs by sector for some fixed output $\mathrm{y}$ :

$$
\begin{aligned}
& T C\left(y_{i 3}\right)>T C\left(y_{i 2}\right) \geq T C\left(v_{i 1}\right) \\
& \text { where } T C\left(y_{i 3}\right)-T C\left(y_{i 2}\right)=f[M C, \text { HOMO }] \text { and } T C\left(y_{i 2}\right)-T C\left(y_{i 1}\right)=g[M C]
\end{aligned}
$$

MC refers to the differences in monitoring costs which derive from organizational form as well as the nature of the service. HOMO refers to the degree of homogeneity of public service preferences within the jurisdiction which affects the costs of writing contracts.

The importance of minimizing production costs to the local government, $\gamma_{i}$, should be greater in communities with constraints on spending. The importance of minimizing transaction costs, $\delta_{i}$, should be greater in communities where the service constituency is large and politically powerful.

\section{Empirical Specification}

Consider now the empirical specification of our model. The production and transaction cost characteristics of the alternatives define the utility, $U_{i j}$, which the local government $i$ has for each alternative $j$. We can divide the utility of each alternative into a deterministic and random component:

$$
U_{i j}=V_{i j}+\varepsilon_{i j}
$$

where $V_{i j}$ is a function of the measured characteristics 
$\varepsilon_{i j}$ is the disturbance

Since the local government is assumed to select the alternative that maximizes its utility (by minimizing the weighted sum of production and transaction costs), the probability that alternative $j$ will be chosen by local government $i$ is given by:

$$
P_{i j}=P\left(V_{i j}+\varepsilon_{i j} \geq V_{i k}+\varepsilon_{i k}\right), \forall j=1,2,3 j \neq k
$$

The deterministic portion of utility, $V_{i j^{\prime}}$ is assumed to be linear in its parameters and according to our theory includes both alternative (sector) and jurisdictional characteristics, i.e.:

$$
v_{i j}=B^{\prime} A_{i j}+\alpha_{i j} J_{i}+\varepsilon_{i j}
$$

where $A_{i j}$ are the characteristics of alternative $j$ as perceived by decision maker $i$; and $J_{i}$ is the vector of characteristics of the ith local government.

If we assume the disturbances are independently and identically distributed with a Gumbel $^{10}$ (or type 1 extreme value distribution); then Equations (1) and (2). yield the following mixed multinomial logit model: ${ }^{11}$

$$
P_{i j}=\frac{\exp \left(B^{\prime} A_{i j}+\alpha_{i j} J_{i}\right)}{\sum_{k=1}^{3} \exp \left(B^{\prime} A_{i k}+\alpha_{k} J_{i}\right)}
$$

Equation (3) is estimated using data on three local health services: hospital services, drug and aicohol prevention and treatment programs, and mental health programs.

We focus on health services for several reasons. First, the health care industry is one in which viable producer choices exist in all three sectors, particularly with the expansion of for-profit health care providers in recent years. Second, local health services provide an interesting case since they are frequently contracted and such contracts are distributed

\footnotetext{
${ }^{10}$ The assumption of a Gumbel distribution can be defended as an approximation to the normal density.

${ }^{11}$ This particular multinomial model derives from the work of McFadden (1973). See Maddala (1983) or 8enAkiva and Lerman (1985) for the derivation.
} 
across all three sectors (Ferris and Graddy, 1986). Finally, the delivery of health services are an important part of local government's service delivery obligations. Thus, these services provide an appropriate basis for an analysis of the determinants of the local government's contractor choice decision.

\section{Data}

Data collected by the International City Management Association in 1982 provide the incidence of city health contracting by sector. ${ }^{12}$ In order to estimate the contractor choice model, the survey data are merged with information on community fiscal and demographic characteristics obtained from secondary sources. The primary source of demographic data is the 1983 County and City Data Book which only contains information on cities with a population in excess of 25,000 . Consequently, jurisdictions with a population less than 25,000 were truncated from our sample, and one is cautioned from drawing inferences from this analysis for small cities. ${ }^{13}$

After observations with missing data are deleted, the working sample of jurisdictions is 583. Of these cities, 107 provide hospital services, 85 percent of which contract; 179 provide drug/alcohol treatment programs, 85 percent of which contract; and 123 provide mental health services, 86 percent of which contract. ${ }^{4}$ Observations for each health service contracted were pooled to create the data set. The pooled data set contains 309 observations. Of these, 32 percent represent contracts with other governments; 48 percent represent contracts with nonprofit organizations; and 20 percent represent contracts with for-profit firms. ${ }^{15}$

\footnotetext{
12 Between March and June 1982, the chief administrative officers of 3130 cities were surveyed about the services they provide and how they are delivered to citizens. The survey collected information on the service delivery arrangements of local governments for approximately 60 public services. Forty-nine percent of the cities responded. For additional details on the survey see: International City Management Association (1982).

${ }^{13}$ The main effect of this truncation is to eliminate a class of cities which have a slightly higher rate of contracting for local health services than for cities above our population threshold.

${ }^{14}$ Contracting may involve no public inputs lexclusive external production), or may include public employees used in conjunction with contracts imixed productiont.

${ }^{15}$ The dependent variable is constructed as the most private form of contractor. For example, if both nonprofits and for-profits receive contracts for a service, the contractor is recorded as for-profit. This specification is necessary because the estimation technique utilized does not allow the selection of multiple alternatives by a given decision maker.
} 
The determinants of contractor choice (vectors $A$ and $J$ ) are measured as follows. Consider first the production cost variables. Our model specifies two determinants of production cost differences across sectors, managerial incentives and input rigidities. Managerial incentive differences across sectors are captured with the ordinal variable, $M I_{j}$, which assumes a value of 1 if $j=1,2$ if $j=2$, and 3 if $j=3$, constant over jurisdictions. This captures the incentives for efficiency which are strongest in for-profit organizations and weakest in public organizations. We expect the coefficient to be positive, i.e., decision makers prefer contractors with managerial incentives to minimize production costs.

Input rigidities, especially with respect to labor, distinguish public versus private sector production costs. A major manifestation of this distinction is the difference in labor costs across sectors. Therefore we define $L C_{i j}$ as the labor costs by sector and jurisdiction. Specifically, $L C_{i 1}=$ public sector salaries in jurisdiction $i, L C_{i 2}=L C_{i 3}=$ private sector salaries in jurisdiction $i$. We expect a negative coefficient, i.e., contractors with lower labor costs will be preferred.

The interest of the jurisdiction in production costs. $Y_{i}$, is captured with three measures of fiscal constraints: a tax limit variable, a tax burden variable, and a community wealth measure, and with a government form variable. FISLIM is a fiscal limit categorical variable, which has a value of one if a jurisdiction has a property tax limit and a value of zero otherwise. The fiscal limit variable simply reflects legal limits. The existence of a limit is expected to increase the importance of production cost savings to the community. TAX is locally raised tax revenues per capita. This variable captures the community's ability and willingness to raise revenues on its own. The effect of TAX is difficult to predict. Higher per capita taxes may suggest greater likelihood of constituency resistance to further government spending. This should make local officials more aware of the need for reduced costs. On the other hand, low per capita taxes may indicate a poor tax base and thus a relative inability to raise revenues. This is likely to increase cost-reducing pressures. However, we hope to account for this latter effect by including a separate measure of community tax base: VALOWN, the median value of owner-occupied housing in the jurisdiction. This measure of community wealth is a reasonable indicator of the tax base given the pivotal role of the property tax in local finance, albeit diminished in recent vears. Finally, the government form variable, MGR, reflects the degree to which the local government is administered by a professional manager. It has a value of 1 if the jurisdiction has a council-manager form of government, and 0 otherwise. Councilmanager governments are assumed to be more sensitive to minimizing costs. 
Our model specifies two determinants of transaction cost differences across sectors, contract writing costs and monitoring costs. Contract writing is less costly when service specifications are easier to articulate. More homogeneous communities are likely to have more stable service preferences and, thus, lower writing costs. We include a racial composition measure, $N W_{i}$, the proportion of nonwhites in jurisdiction $i$, as a measure of jurisdiction homogeneity with respect to race. It is included in quadratic form since both high and low proportions of nonwhites indicate community homogeneity.

Monitoring costs are a function of both the organizational form of the contractor and the ease of monitoring the service. Sector differences in monitoring costs are represented with the ordinal variable $M C_{j}$, which assumes a value of 1 for $j=3$, and a value of 2 for $j=1$ or 2. $M C_{j}$, which is constant across jurisdictions, represents the higher monitoring costs inherent in contracts with the for-profit sector, due to the presumption that they have a stronger incentive, by virtue of their assignable property rights, to shirk on contracts. Service differences in monitoring costs are represented by $M C_{\mathrm{s}^{\prime}}$, which assumes a value of 1 if the contracted service is hospital and a value of 2 if the contracted service is mental health or drug/alcohol prevention and treatment. Higher values of $M C_{s}$ represent less tangible service outputs. It is more difficult to assess the quality of mental health and drug/alcohol prevention and treatment services than of hospital services. Monitoring costs are important for services with less tangible outputs and relatively unimportant for services with tangible outputs. Therefore, we create an interactive variable: $M C_{j s}=$ $M C_{j}{ }^{*} M C_{s}$. This specification captures the effect of service on the importance of organizational form differences in monitoring costs. For intangible services, the organization form advantages of the nonprofit and other-government sectors becomes more important. We expect a positive coefficient, i.e., the contracting government will prefer, when monitoring matters, the contractors with low monitoring costs.

The strength of the jurisdiction's preferences with respect to service quality, $\delta$. determines it's willingness to incur monitoring costs. We use the size of the service constituency as a proxy. The primary constituency of local health services are the poor; therefore we measure constituency strength with $P O V_{i}$ the percentage of the jurisdiction's population that is below the poverty level.

Finally, we must consider the feasibility of the choice set for a jurisdiction. Some jurisdictions do not have external producer options in all sectors for all services. Ideally, 
if we had precise availability measures, we could use them to define the choice set for each jurisdiction. Unfortunately, data do not exist on all the external suppliers of these services at the local level, so we use the available information to incorporate two availability measures in our model. The American Hospital Association collects data on the number of hospitals by sector including those that provide mental health and drug/alcohol treatment services. Therefore, we define $A B_{i j}$ as the number of beds in hospitals providing the services in jurisdiction $i$ and sector $j$. The available beds measure does not capture all suppliers of drug/alcohol and mental health services, but it can be perceived as a proxy for the distribution of external suppliers by sector. There is no apparent reason to assume that nonhospital suppliers of these health services are distributed significantly differently across sectors.

In addition to $A B$, we specify a jurisdictional choice set variable, SMSA. SMSA is a dummy variable, assuming a value of 1 if jurisdiction $i$ is located within an SMSA and 0 otherwise. This variable captures the option of jurisdictions located within SMSAS to cross jurisdictional boundaries to obtain external producers. This control is needed since $A B$ is jurisdictionally defined.

To summarize, the production cost variables are $M I_{\mathrm{i}}, L C_{\mathrm{ij}}$, EISLIM TAX $_{\mathrm{i}}, V A L O W N_{\mathrm{i}}$, and $M G R_{i}$; the transaction cost variables are $M C_{j s^{\prime}} N W_{i^{\prime}}$ and $P O V_{i}$ and the variables which define the feasible choice set are $A B_{i j}$ and $S M S A_{i}$. The data set is summarized in Table 1 which includes the variable descriptions, sources and descriptive statistics.

\section{Multinomial Estimation}

It is useful for an understanding of the results to separate these explanatory variables into those that are part of the A vector, which vary across alternatives or alternatives and jurisdictions or services, and those that are part of the $J$ vector and only vary across jurisdictions. The $A$ vector includes $M I_{j}, L C_{i j}, M C_{j s^{\prime}}$ and $A B_{i j}$; the $J$ vector includes EISLIM TAX $_{\mathrm{i}}$, VALOWN $_{\mathrm{i}}$, MGR $_{\mathrm{i}}, N \mathrm{~W}_{\mathrm{i}}$, POV $_{\mathrm{i}}$, and SMSA. Estimation vields a single coefficient for each $A$ variable (alternative characteristic) and a set of coefficients associated with paired atternatives for each $\downarrow$ variable (jurisdictional characteristic). The coefficients of the A variables give the value of the sector characteristics to the decision maker. The coefficients of the $J$ variables are the usual multinomial logit parameter estimates and show the effect of the jurisdictional characteristics on the probability of choosing one alternative relative to another aiternative. 


\section{Results}

The results of the estimation of Equation (3) are presented in Table 2. The first column contains the coefficients associated with the characteristics of alternatives (the $A$ vector). The coefficients presented in the second column (denoted NP/OG) are estimates of the importance of the jurisdictional variables in the choice of a nonprofit organization over an external public organization. Similarly, the third column (denoted FP/OG) presents coefficients relevant to the choice of a for-profit organization over an external public organization, and the fourth column (denoted FP/NP) refers to the choice of a for-profit organization relative to a nonprofit one.

The two production cost variables in the $A$ vector, $M I$ and $L C$, have statistically significant coefficients. As predicted, the sector differences in managerial incentives affect the contractor choice. Decision makers place higher value on managerial incentives that are conducive to minimizing production costs (high values of $M I$ ): Labor cost differences, which are a manifestation of managerial discretion in input selection, also affect the contractor choice. Decision makers prefer contractors with lower labor costs. These results reinforce the contention in the service delivery literature that contracting is an attractive alternative due to the perceived efficiencies resulting from managerial incentives and discretion.

In addition, two of the variables which measure the importance of production costs to the jurisdiction have statistically significant coefficients - MGR and FISLIM. As predicted, local governments with a council-manager form of government prefer the private sectors, both for-profit and nonprofit, over other governments. This result is consistent with the argument advanced by the local government "reform" movement of the 1920s, that professional administration of cities would yield more efficient service delivery (Zax, 1985).

Although FISLIM has a significant coefficient, its sign is not as predicted. The results indicate that jurisdictions with legal limits on spending and taxing prefer other governments as contractors over the nonprofit sector and the for-profit sector. The opposite was hypothesized. This result might reflect the existence, in fiscally conservative areas such as California, of contract cities, i.e., cities created to provide services, but which rely exclusively on their counties for service production (Miller, 1981).

Transaction costs also affect the contractor choice. The transaction cost variable, $M C$ has 
a statistically significant coefficient. As predicted, for intangible services, the monitoring cost differences across organizational form affect the contractor choice with local governments preferring those forms that minimize monitoring costs (high values of $M C$ ). This result supports our theory that transaction costs, as related to organizational type and service, are also important to the contractor choice decision.

The results also indicate the importance of a viable choice set in this decision. The jurisdictional choice set variable, SMSA, has a statistically significant coefficient. Local governments located within SMSAs prefer to contract with other governments over both for-profit and nonprofit organizations. Although the statistical unimportance of the sector specific measure of available producers $(A B)$ is disappointing, the importance of the jurisdictional measure is suggestive of the role of the availability of external producers in this decision. Cities in SMSAs have other governments, both other cities and counties, from which to choose and they prefer these contractors over private ones.

In summary, the empirical analysis indicates that both production costs and transaction costs weigh in the contractor choice decision for cities which choose to externally produce health services. The alternative specific variables are important, with three of the four measures being statistically significant and having the predicted effects. The results for the community level variables, although somewhat weaker, also lend support to the theory with respect to the weight given to production costs and supplier availability.

One surprise in the results is the inability of community level variables to discern local government choices between for-profit and nonprofit contractors. This may reflect the small number of contracts with for-profit health providers, or it may indicate that the pivotal choice for the city is between other governments and the private sector, either for-profit or nonprofit. Better community measures relating to differences between the nonprofit sector and the for-profit sector are needed to yield a more definitive interpretation. 


\section{Conclusion}

The recognition that service delivery costs entail both production and transaction costs is essential to understanding the balancing act that local governments face between cost savings and accountability and explains the importance of sector (or organizational form) in the local government's contractor choice decision. The results provide support for our theory -both production costs variables and transaction cost variables are important. The significance of the production costs variables reinforce the notion that contracting is a method of reducing the costs of producing publicly provided services. However, the significance of the transaction costs variable suggest that contracting cities are concerned with the costs of monitoring contracts, and may prefer other governments or nonprofit organizations. This finding suggests that claims of the relative efficiency of the for-profit sector may be overstated, and that contracts with other governments and nonprofits may result in lower service delivery costs. The implication for the current contracting debate is that the organizational form of the contractor may be pivotal for services that are hard to monitor.

Of course sector choice is only meaningful if external producers exist in more that one sector. Indeed the results indicate that an important factor influencing contractor choice for the health services in our sample is the availability of contractor options. Although the alternative specific variable is not significant, the community level variable, SMSA, is. This finding implies that contracting decisions should not be based simply on demands for contracting, but also on the availability of contracting options. This is particularly important if the net efficiencies in service delivery vary systematically by the contractor's sector. In addition, this finding suggests that in order to capitalize on the potential efficiencies of contracting, local governments may want to encourage the development of suppliers. ${ }^{16}$

This initial effort at better understanding the contractor choice decision indicates that further work incorporating the organizational economics literature with the public service delivery literature will be fruitful. Future analyses should examine the contractor choice across considerably different types of services, e.g., social services, recreational services,

This is consistent with Salamon's (1987) view of government-nonprofit relations at the federal level and with OeHoog's (1984) at the local level. 
and transportation, and well as contractor choices over time as more organizations in the three sectors become involved in the particular service industries. 
Table 1: Variable Definitions and Descriptive Statistics

Variable $^{3}$

Mean'(SD)

\begin{tabular}{|c|c|c|}
\hline \multicolumn{3}{|c|}{ Alternative-specific Variables } \\
\hline$L C$ & $\begin{array}{l}\text { Sector-specific salaries; private service } \\
\text { sector salaries used for both private sectors(1) }\end{array}$ & $13.04(2.84)$ \\
\hline$A B$ & $\begin{array}{l}\text { Number of beds in hospitals providing } \\
\text { the service per } 1000 \text { population( } 2 \text { ) }\end{array}$ & $11.99(27.79)$ \\
\hline \multicolumn{3}{|c|}{ Jurisdiction-specific Variables } \\
\hline FISLIM & $\begin{array}{l}1 \text { if jurisdiction has property tax limit; } \\
0 \text { otherwise( } 3 \text { ) }\end{array}$ & $\begin{array}{l}.56 \\
.44\end{array}$ \\
\hline TAX & Local taxes per capita(1) & $233.72(204.66)$ \\
\hline VALOWN & Median value of owner-occupied housing $(I)$ & $5.42(2.17)$ \\
\hline MGR & $\begin{array}{l}1 \text { if government has manager-council form; } \\
0 \text { otherwise }(4)\end{array}$ & $\begin{array}{l}.66 \\
.34\end{array}$ \\
\hline NW & Nonwhite proportion of the populatiori(I) & $.16(.14)$ \\
\hline POV & $\begin{array}{l}\text { Percent of the population which is below } \\
\text { federal poverty threshold(I) }\end{array}$ & $11.57(5.35)$ \\
\hline SMSA & $\begin{array}{l}1 \text { if the jurisdiction within SMSA } \\
0 \text { otherwise(I) }\end{array}$ & $\begin{array}{r}.91 \\
.19\end{array}$ \\
\hline
\end{tabular}

-The number at the end of each variable description refers to the source:

1 U.S. Bureau of the Census, 1984

2 American Hospital Association, 1983

s Advisory Commission on Intergovernmental Relations, 1984

4 International City Management Association, 1982b

-For categorical variables, the numbers in this column are the relative frequencies.

This table omits the two ordinal variables created by the authors. MI, managerial incentives, is assigned the value 1 if external public; 2 if nonprofit; and 3 if for-profit. $M C$, monitoring costs, is an interaction term between $M C y$ monitoring costs associated with organizational form, (1 if for-profit; and 2 if nonprofit or other government), and $M C_{s}$, service type, (1 if hospital; and 2 if mental health or drug/alcohol prevention treatment services). 


\section{Table 2: Mixed Multinomial Logit Parameter Estimates}

$\begin{array}{ll}\text { Variable } \\ M I & 2.90^{\star \star \star \star}(.672) \\ M C & 2.24^{\star \star \star \star}(.318) \\ L C & -.086^{\star \star}(.036) \\ A B & .0016(.0029)\end{array}$

EISLIM

$-1.19^{* \star \star \star}(.300) \quad-.828^{\star \star}(.403) \quad .358(.352)$

TAX

$.00085(.00087) \quad .00047(.0012) \quad-.00038(.0017)$

VALOWN

$-.146(.084)$

$-.105(.084)$

$.040(.092)$

MGR

$.883^{\star \star \star} \cdot(.329)$

$1.39^{* \hbar \star}(.451)$

$.503(.425)$

.NW

$-.551(3.52)$

$1.14(4.72)$

$-.402(4.40)$

$N W^{2}$

$-.040(.061)$

$-.018(.085)$

$.022(.078)$

POV

$.027(.039)$

$-.012(.060)$

$-.039(.049)$

SMSA

$-1.84^{\star \star \star \star}(.594) \quad-2.20^{\star \star \star \star}(.759) \quad-.356(.551)$

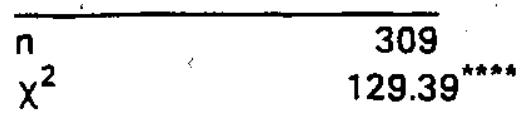

NOTE: Standard errors in parentheses. Significance levels are indicated by asterisks as follows: ${ }^{* \star \star *}$ denotes .005 level; ${ }^{* \star *}$ denotes .01 level; ${ }^{* *}$ denotes .05 level. 


\section{References}

Advisory Commission on Intergovernmental Relations. Significant Features of Fiscal Federalism, 1982-83. Technical Report M-137, Advisory Commission on Intergovernmental Relations, January 1984.

American Hospital Association. American Hospital. Association Guide to the Health Care Field. Chicago, ILAmerican Hospital Association, 1983.

Ben-Akiva, Moshe and Steven R. Lerman. Discrete Choice Analysis: Theory and Application to Travel Demand. Cambridge, Mass:MIT Press, 1985.

Borcherding, Thomas E., Werner W. Pommerehne, and Friedrich Schneider. Comparing the Efficiency of Private and Public Production: The Evidence from Five Countries. Journal of Economics, .1982, Supplement 2,127-156.

Borcherding, Thomas E. Some Revisionist Thoughts on the Theory of Public Bureaucracy. Forthcoming, European Journal of Political Economy.

DeHoog, Ruth Hoogland. Contracting out for Human Services: Economic, Political and Organization Perspectives. Albany:State University of New York Press, 1984.

Ferris, James. The Decision to Contract Out: An Empirical Analysis. Urban Affairs Quarterly, December 1986, 22(2), 289-311.

Ferris, James and Elizabeth Graddy. Contracting Out: For What? With Whom? Public Administration Review, July/August 1986, 46(4), 332-344.

Ferris, James and Elizabeth Graddy. Production Choices for Local Government Services. Journal of Urban Affairs, 1988, 10(3), 273-289.

Hansmann, Henry B. The Role of Nonprofit Enterprise. Yale Law Journal, April 1980 89, 835-901.

Hansmann, Henry. The Effect of Tax Exemption and Other Factors on the Market Share of Nonprofit Versus For-profit Firms. National Tax Journal, March 1987, 40(1), 71-82.

International City Management Association. Alternative Approaches for Delivering Public Services. Urban Data Service Report Vol. 14, No. 10, International City Management Association, October 1982.

James, Estelle and Susan Rose-Ackerman. The Nonprofit Enterprise in Market Economies. New York:Harwood Academic Publishers, 1986.

Krashinsky, Michael. Transaction Costs and a Theory of the Nonprofit Organization. In Susan Rose-Ackerman (Ed.), The Economics of Nonprofit Institutions, New York: Oxford University Press, 1986.

Maddala, G. S. Limited-Dependent and Qualitative Variables in Econometrics. Cambridge:Cambridge University Press, 1983. 
McFadden, Daniel. Conditional Logit Analyis of Qualitative Choice Behavior. In P. Zarembka (Ed.), Frontiers in Econometrics, New York: Academic, 1973.

Mehay, Stephen L and Rodolfo A. Gonzalez. Economic incentives under contract supply of local government services. Public Choice, 1985, 46, 79-86.

Miller, Gary J. Cities by Contract The Politics of Municipal Incorporation. Cambridge, Ma.Massachusetts Institute Technology Press, 1981.

Niskanen, William A., Jr. Bureaucracy and Representative Government. Chicago:Aldine-Atherton, 1971.

Salamon, Lester. Partners in Public Service: The Scope and Theory of Government Nonprofit Relations. In Walter W. Powell (Ed.), The Nonprofit Sector: A Research Handbook, New Haven: Yale University Press, 1987.

Sonenblum, Sidney, John J. Kirlin, and John C. Ries. How Cities Provide Services: An Evaluation of Alternative Delivery Structures. Cambridge:Ballinger, 1977.

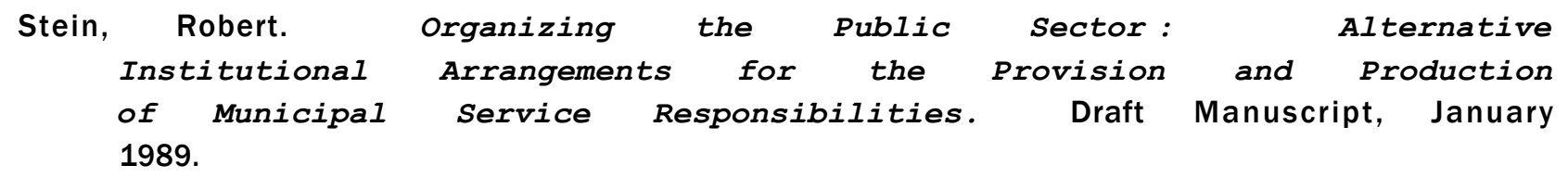

U.S. Bureau of the Census. County and City Data Book, 1983. Washington, DC:Department of Commerce, 1984.

Weisbrod, Burton. The Nonprofit Economy. Cambridge, MA:Harvard University Press, 1988.

Williamson, Oliver E. The Economic Institutions of Capitalism: Firms, Markets, Relational Contracting. New York:The Free Press, 1985.

Zax, Jeffrey. Economic Effects of Municipal Government Institutions: National Bureau of Economic Research Working Paper No. 1657, July 1985. 